\title{
Analytical Approximate Solution of Nonlinear Differential Equation Governing Jeffery-Hamel Flow with High Magnetic Field by Adomian Decomposition Method
}

\author{
D. D. Ganji, M. Sheikholeslami, and H. R. Ashorynejad
}

Faculty of Mechanical Engineering, Babol Noshirvani University of Technology, Mazandaran, P.O. Box 484, Babol 47148-71167, Iran

Correspondence should be addressed to D. D. Ganji, ddg_davood@yahoo.com

Received 21 February 2011; Accepted 7 April 2011

Academic Editors: G. Garcea and P. B. Mucha

Copyright (C) 2011 D. D. Ganji et al. This is an open access article distributed under the Creative Commons Attribution License, which permits unrestricted use, distribution, and reproduction in any medium, provided the original work is properly cited.

\begin{abstract}
The magnetohydrodynamic Jeffery-Hamel flow is studied analytically. The traditional NavierStokes equation of fluid mechanics and Maxwell's electromagnetism governing equations reduce to nonlinear ordinary differential equations to model this problem. The analytical tool of Adomian decomposition method is used to solve this nonlinear problem. The velocity profile of the conductive fluid inside the divergent channel is studied for various values of Hartmann number. Results agree well with the numerical (Runge-Kutta method) results, tabulated in a table. The plots confirm that the method used is of high accuracy for different $\alpha, \mathrm{Ha}$, and Re numbers.
\end{abstract}

\section{Introduction}

The flow of fluid through a divergent channel is called Jeffery-Hamel flow since introducing this problem by Jeffery [1] and Hamel [2] in 1915 and 1916, respectively. On the other hand, the term of magnetohydrodynamic (MHD) was first introduced by Bansal [3] in 1994. The theory of magnetohydrodynamics is inducing current in a moving conductive fluid in presence of magnetic field; such induced current results in force on ions of the conductive fluid. The theoretical study of magnetohydrodynamic (MHD) channel has been a subject of great interest due to its extensive applications in designing cooling systems with liquid metals, MHD generators, accelerators, pumps, and flow meters [4-7].

In fluid mechanics most of the problems are nonlinear. It is very important to develop efficient methods to solve them. Up to now, it is very difficult to obtain analytical 
approximations of nonlinear partial differential equations even though there are highperformance computers and computation software. The small disturbance stability of Magnetohydrodynamic stability of plane Poiseuille flow has been investigated by Makinde and Motsa [8] and Makinde [9] for generalized plane Couette flow. Their results show that magnetic field has stabilizing effects on the flow. Considerable efforts have been done to study the MHD theory for technological application of fluid pumping system in which electrical energy forces the working conductive fluid. Damping and controlling of electrically conducting fluid can be achieved by means of an electromagnetic body force (Lorentz force) produced by the interaction of an applied magnetic field and an electric current that usually is externally supplied. Harada et al. [10] studied the fundamental characteristics of linear Faraday MHD theoretically and numerically. In 2005, Anwari et al. [11] continued the Harada et al. [10] work numerically and theoretically, for various loading configurations. Jang and Lee [12] emphasized on the idea that, in such problems, the moving ions drag the bulk fluid with themselves and such MHD system induces continues pumping of conductive fluid without any moving part. Homsy et al. [13] worked and developed the same idea mentioned above. The purpose of the current work is to study the mechanics of the fluid through a divergent channel in presence of electromagnetic field (Figure 1).

The Adomian decomposition method (ADM) is used to solve a wide range of physical problems. One of the semiexact methods which does not need linearization or discretization is Adomian decomposition method, and several modifications have improved its ability [1416].

An advantage of this method is that it can provide analytical approximation or an approximated solution to a rather wide class of nonlinear (and stochastic) equations without linearization, perturbation, closure approximation, or discretization methods. Unlike the common methods, that is, weak nonlinearity and small perturbation which change the physics of the problem due to simplification, ADM gives the approximated solution of the problem without any simplification. Thus, its results are more realistic [17]. ADM abilities have attracted many authors to use this method for solving fluid dynamic problems.

Jafari and Daftardar-Gejji [18] presented a modified ADM to solve a system of nonlinear equations, which yielded a series of solutions with faster accelerated convergence than the series obtained by the standard ADM. Bulut et al. [19] studied viscous incompressible flow through orifice. Allen and Syam [20] and Wang [21] investigated nonhomogeneous and classical Blasius equation by ADM. Soh [22] applied ADM to solve thin film equation. Hashim [23] presented the Adomian decomposition method for solving BVPs for fourthorder integrodifferential equations and the Blasius equation [24]. Kechil and Hashim [25] presented a nonperturbative solution of free-convective boundary-layer equation by ADM. Chang [26] presented a decomposition solution for fins with temperature-dependent surface heat flux. Arslanturk [27] inspected on the fins efficiency of convective straight fins with temperature-dependent thermal conductivity using the decomposition method. ADM also has been used by several researchers to solve a wide range of physical problems in various engineering fields such as fluid flow and porous media simulation [28-31] and other nonlinear systems [32-38]. In recent years some researchers used new methods to solve these kinds of problems [39-41].

In this paper, we have applied ADM to find the approximate solutions of nonlinear differential equations governing the MHD Jeffery-Hamel flow, and a comparison between the results and the numerical solution has been provided. The numerical results of this problem are done using Maple 12. 


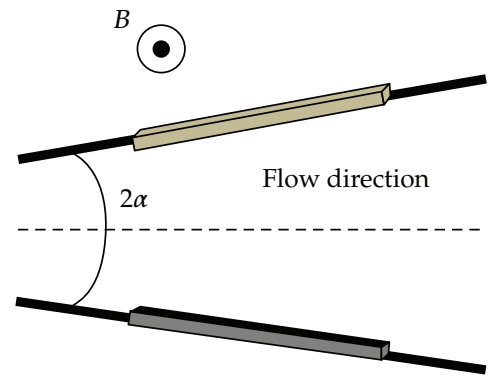

Figure 1: Geometry of the MHD Jeffery-Hamel flow.

\section{Governing Equations}

Consider a system of cylindrical polar coordinates $(r, \theta, z)$ which steady two-dimensional flow of an incompressible conducting viscous fluid from a source or sink at channel walls, lie in planes, and intersect in the axis of $z$, assuming purely radial motion which means that there is no change in the flow parameter along the $z$ direction. The flow depends on $r, \theta$, and further assume that there is no magnetic field in the $z$-direction. In the reduced form of continuity, Navier-Stokes and Maxwell's equations are [40]

$$
\begin{gathered}
\frac{\rho \partial}{r \partial r}(r u(r, \theta))=0 \\
u(r, \theta) \frac{\partial u(r, \theta)}{\partial r}=-\frac{1}{\rho} \frac{\partial P}{\partial r}+v\left[\frac{\partial^{2} u(r, \theta)}{\partial r^{2}}+\frac{1}{r} \frac{\partial u(r, \theta)}{\partial r}+\frac{1}{r^{2}} \frac{\partial^{2} u(r, \theta)}{\partial \theta^{2}}-\frac{u(r, \theta)}{r^{2}}\right]-\frac{\sigma B_{0}^{2}}{\rho r^{2}} u(r, \theta), \\
\frac{1}{\rho r} \frac{\partial P}{\partial \theta}-\frac{2 v}{r^{2}} \frac{\partial u(r, \theta)}{\partial \theta}=0
\end{gathered}
$$

where $B_{0}$ is the electromagnetic induction, $\sigma$ the conductivity of the fluid, $u(r)$ the velocity along radial direction, $P$ the fluid pressure, $v$ the coefficient of kinematic viscosity, and $\rho$ the fluid density. Considering $u_{\theta}=0$ for purely radial flow, one can define the velocity parameter as

$$
f(\theta)=r u(r) .
$$

Introducing the $\eta=\theta / \alpha$ as the dimensionless degree, the dimensionless form of the velocity parameter can be obtained by dividing that to its maximum value as

$$
f(\eta)=\frac{f(\theta)}{f_{\max }}
$$


Substituting (2.5) into (2.2) and (2.3) and eliminating $P$, one can obtain the ordinary differential equation for the normalized function profile as [10]

$$
f^{\prime \prime \prime}(\eta)+2 \alpha \operatorname{Re} f(\eta) f^{\prime}(\eta)+(4-\mathrm{Ha}) \alpha^{2} f^{\prime}(\eta)=0
$$

with the following reduced form of boundary condition

$$
f(0)=1, \quad f^{\prime}(0)=0, \quad f(1)=0 .
$$

We introduce the Reynolds number and the Hartmann number based on the electromagnetic parameter as follows, respectively:

$$
\begin{gathered}
\operatorname{Re}=\frac{f_{\max } \alpha}{v}=\frac{U_{\max } r \alpha}{v}\left(\begin{array}{c}
\text { divergent-channel: } \alpha>0, f_{\max }>0 \\
\text { convergent-channel: } \alpha<0, f_{\max }<0
\end{array}\right), \\
\mathrm{Ha}=\sqrt{\frac{\sigma B_{0}^{2}}{\rho v}} .
\end{gathered}
$$

\section{Fundamentals of Adomian Decomposition Method (ADM)}

Consider equation $F u(t)=g(t)$, where $F$ represents a general nonlinear ordinary or partial differential operator including both linear and nonlinear terms. The linear terms are decomposed into $L+R$, where $L$ is easily invertible (usually the highest order derivative) and $R$ is the remainder of the linear operator. Thus, the equation can be written as [14]:

$$
L u+N u+R u=g
$$

where $N u$ indicates the nonlinear terms. By solving this equation for $L u$, since $L$ is invertible, we can write

$$
L^{-1} L u=L^{-1} g-L^{-1} R u-L^{-1} N u
$$

If $L$ is a second-order operator, $L^{-1}$ is twofold in definite integral. By solving (3.2), we have $[14]$

$$
u=A+B t+L^{-1} g-L^{-1} R u-L^{-1} N u,
$$

where $A$ and $B$ are constants of integration and can be found from the boundary or initial conditions. Adomian method assumes that the solution $u$ can be expanded into infinite series as

$$
u=\sum_{n=0}^{\infty} u_{n}
$$


Also, the nonlinear term $N u$ will be written as

$$
N u=\sum_{n=0}^{\infty} A_{n}
$$

where $A_{n}$ are the special Adomian polynomials. By specified $A_{n}$, the next component of $u$ can be determined:

$$
u_{n+1}=L^{-1} \sum_{n=0}^{n} A_{n}
$$

Finally, after some iteration and getting sufficient accuracy, the solution of the equation can be expressed by (3.5).

In (3.6), the Adomian polynomials can be generated by several means. Here we used the following recursive formulation [41]:

$$
A_{n}=\frac{1}{n !}\left[\frac{d^{n}}{d \lambda^{n}}\left[N\left(\sum_{i=0}^{n} \lambda^{i} u_{i}\right)\right]\right]_{\lambda=0}, \quad n=0,1,2,3, \ldots
$$

Since the method does not resort to linearization or assumption of weak nonlinearity, the solution generated is in general more realistic than those achieved by simplifying the model of the physical problem.

\section{Application}

According to (3.1), (2.6) must be written as follows:

$$
L f=-2 \operatorname{Re} \alpha f f^{\prime}-(4-\mathrm{Ha}) \alpha^{2} f^{\prime},
$$

where the differential operator $L$ is given by $L=d^{3} / d \eta^{3}$. Assume that the inverse of the operator $L$ exists and it can be integrated from 0 to $\eta$, that is, $L^{-1}=\iiint_{0}^{\eta}(\cdot) d \eta d \eta d \eta$.

Operating with $L^{-1}$ on (4.1) and after exerting boundary condition on it, we have

$$
f(\eta)=f(0)+f^{\prime}(0) \eta+f^{\prime \prime}(0) \frac{\eta^{2}}{2}+L^{-1}(N u),
$$

where

$$
N u=-2 \operatorname{Re} \alpha f(\eta) f^{\prime}(\eta)-(4-\mathrm{Ha}) \alpha^{2} f^{\prime}(\eta) .
$$


ADM introduced the following expression:

$$
\begin{gathered}
f(\eta)=\sum_{m=0}^{\infty} f_{m}(\eta) \\
f(\eta)=\sum_{m=0}^{\infty} f_{m}=f_{0}+L^{-1}(N u) .
\end{gathered}
$$

To determine the components of $f_{m}(\eta)$ the $f_{0}(\eta)$ is defined by applying the boundary condition of (2.7), and by assuming $f^{\prime \prime}(0)=\beta$,

$$
\begin{aligned}
& f_{0}(\eta)=1+\beta \frac{\eta^{2}}{2} \\
& f_{1}(\eta)=\left(\frac{-1}{120}\right) \alpha \operatorname{Re} \beta^{2} \eta^{6}-\frac{1}{4}\left(\frac{1}{3} \alpha \operatorname{Re} \beta+\frac{1}{6}(4-\mathrm{Ha}) \alpha^{2} \beta\right) \eta^{4} \\
& -\frac{1}{120}(4-\mathrm{Ha}) \alpha^{2} \beta \eta^{5}-\frac{1}{6}(4-\mathrm{Ha}) \alpha^{2} \eta^{3} \\
& f_{2}(\eta)=\left(\frac{1}{10800}\right) \alpha^{2} \operatorname{Re}^{2} \beta^{3} \eta^{10}+\frac{1}{7560} \alpha^{3} \operatorname{Re}(4-\text { На }) \beta^{2} \eta \\
& -\frac{1}{8}\left(\frac{1}{21} \alpha \operatorname{Re}\left(-\frac{1}{12} \alpha \operatorname{Re} \beta-\frac{1}{24}(4-\mathrm{Ha}) \alpha^{2} \beta\right) \beta-\frac{1}{420} \alpha^{2} \operatorname{Re}^{2}\right. \\
& \left.+\frac{1}{42} \alpha^{2} \operatorname{Re} \beta\left(-\frac{1}{3} \alpha \operatorname{Re} \beta-\frac{1}{6}(4-\mathrm{Ha}) \alpha^{2} \beta\right)-\frac{1}{840} \alpha^{3} \operatorname{Re}(4-\mathrm{Ha}) \beta^{2}\right) \eta^{8} \\
& -\frac{1}{7}\left(-\frac{11}{360} \alpha^{3} \operatorname{Re}(4-\mathrm{Ha}) \beta-\frac{1}{720}(4-\mathrm{Ha})^{2} \alpha^{4} \beta\right) \eta^{7} \\
& -\frac{1}{6}\left(\frac{1}{10} \alpha \operatorname{Re}\left(-\frac{1}{3} \alpha \operatorname{Re} \beta-\frac{1}{6}(4-\mathrm{Ha}) \alpha^{2} \beta\right)\right. \\
& \left.+\frac{1}{20}(4-\mathrm{Ha}) \alpha^{2}\left(-\frac{1}{3} \alpha \operatorname{Re} \beta-\frac{1}{6}(4-\mathrm{Ha}) \alpha^{2} \beta\right)\right) \eta^{6} \\
& -\frac{1}{5}\left(-\frac{1}{12} \alpha^{3} \operatorname{Re}(4-\mathrm{Ha})-\frac{1}{720}(4-\mathrm{Ha})^{2} \alpha^{4}\right) \eta^{5}+\frac{1}{40320}(4-\mathrm{Ha})^{2} \alpha^{4} \beta \eta^{8} \\
& -\frac{1}{120}(4-\mathrm{Ha}) \alpha^{2}\left(-\frac{1}{12} \alpha \operatorname{Re} \beta-\frac{1}{24}(4-\mathrm{Ha}) \alpha^{2} \beta\right) \eta^{7}+\frac{1}{720}(4-\mathrm{Ha})^{2} \alpha^{4} \eta^{6}
\end{aligned}
$$

and $f_{3}(\eta), f_{4}(\eta), \ldots$ can be determined in a similar way from (4.5). 


$$
\begin{aligned}
\text { Using } f(\eta)=\sum_{m=0}^{\infty} f_{m}(\eta)=f_{0}(\eta)+f_{1}(\eta)+f_{2}(\eta)+f_{3}(\eta)+\cdots, \text { thus } \\
\begin{aligned}
f(\eta)= & +\beta \frac{\eta^{2}}{2}+\left(\frac{-1}{120}\right) \alpha \operatorname{Re} \beta^{2} \eta^{6}-\frac{1}{4}\left(\frac{1}{3} \alpha \operatorname{Re} \beta+\frac{1}{6}(4-\mathrm{Ha}) \alpha^{2} \beta\right) \eta^{4} \\
- & \frac{1}{24}(4-\mathrm{Ha}) \alpha^{2} \beta \eta^{4}-\frac{1}{2}(4-\mathrm{Ha}) \alpha^{2} \eta^{2}+\left(\frac{1}{10800}\right) \alpha^{2} \operatorname{Re}^{2} \beta^{3} \eta^{10} \\
- & \frac{1}{8}\left(\frac{1}{21} \alpha \operatorname{Re}\left(\frac{-1}{12} \alpha \operatorname{Re} \beta-\frac{1}{12}(4-\mathrm{Ha}) \alpha^{2} \beta\right) \beta-\frac{1}{420} \alpha^{2} \operatorname{Re}^{2} \beta^{2}\right. \\
& \left.+\frac{1}{42} \alpha \operatorname{Re} \beta\left(\frac{-1}{3} \alpha \operatorname{Re} \beta-\frac{1}{3}(4-\mathrm{Ha}) \alpha^{2} \beta\right)-\frac{1}{840}(4-\mathrm{Ha}) \alpha^{2} \beta^{2} \operatorname{Re}\right) \eta^{8} \\
- & \frac{1}{6}\left(-\frac{1}{10} \alpha^{3} \operatorname{Re}(4-\mathrm{Ha}) \beta+\frac{1}{10} \alpha \operatorname{Re}\left(-\frac{1}{3} \alpha \beta \operatorname{Re}-\frac{1}{3}(4-\mathrm{Ha}) \alpha^{2} \beta\right)\right) \eta^{6} \\
- & \frac{1}{4}\left(-\frac{1}{3} \alpha^{3} \operatorname{Re}(4-\mathrm{Ha})-\frac{1}{6}(4-\mathrm{Ha})^{2} \alpha^{4}\right) \eta^{4}+\frac{1}{6720}(4-\mathrm{Ha}) \alpha^{3} \operatorname{Re} \beta^{3} \eta^{8} \\
- & \frac{1}{30}(4-\mathrm{Ha}) \alpha^{2}\left(-\frac{1}{12} \alpha \beta \operatorname{Re}-\frac{1}{6}(4-\mathrm{Ha})^{2} \alpha^{2} \beta\right) \eta^{6}-\frac{1}{24}(4-\mathrm{Ha})^{2} \alpha^{4} \eta^{4}+\cdots
\end{aligned}
\end{aligned}
$$

According to (4.8), the accuracy of ADM solution increases by increasing the number of solution terms $(m)$. For the complete solution of (4.8), $\beta$ should be determined, with boundary condition of $f^{\prime \prime}(0)=\beta$.

\section{Results and Discussion}

In this study the objective was to apply Adomian decomposition method to obtain an explicit analytic solution of the MHD Jeffery-Hamel problem. The magnetic field acts as a control parameter such as the flow Reynolds number and the angle of the walls, in MHD JefferyHamel problems. There is an additional nondimensional parameter that determines the solutions, namely, the Hartmann number. Table 1 shows the value of constant $\beta$ for different $\alpha, \mathrm{Ha}$, and Re numbers at the divergent channel.

For comparison, a few limited cases of the ADM solutions are compared with the numerical results. The comparison between the numerical results and ADM solution for velocity when $\operatorname{Re}=25$ and $\alpha=5^{\circ}$ is shown in Table 2 . The error bar shows an acceptable agreement between the results observed, which confirms the validity of the ADM. In these tables the error is introduced as follows:

$$
\text { \%Error }=\frac{\left|f(\eta)_{\mathrm{NM}}-f(\eta)_{\mathrm{ADM}}\right|}{f(\eta)_{\mathrm{ADM}}} .
$$

\%Error of $\operatorname{ADM}$ for $f(\eta)$ at different steps when $\alpha=5, \operatorname{Re}=50$, and $\mathrm{Ha}=100$ can be seen in Figure 2; it shows that at first we have large error then it decreases and after 12 steps the error becomes minimized. 
Table 1: Value of $f^{\prime \prime}(0)=\beta$ at various $\operatorname{Re}, \mathrm{Ha}$, and $\alpha$.

\begin{tabular}{|c|c|c|c|c|}
\hline $\operatorname{Re}$ & $\alpha$ & $\begin{array}{l}\mathrm{Ha}=100 \\
f^{\prime \prime}(0)=\beta\end{array}$ & $\begin{array}{l}\mathrm{Ha}=200 \\
f^{\prime \prime}(0)=\beta\end{array}$ & $\begin{array}{l}\mathrm{Ha}=300 \\
f^{\prime \prime}(0)=\beta\end{array}$ \\
\hline \multirow{3}{*}{25} & 2.5 & -2.42483 & -2.54507 & -2.66789 \\
\hline & 5 & -3.09259 & -3.57685 & -4.09816 \\
\hline & 7.5 & -3.98607 & -5.14061 & -6.44257 \\
\hline \multirow{3}{*}{50} & 2.5 & -2.77059 & -2.87965 & -2.99167 \\
\hline & 5 & -3.85619 & -4.25077 & -4.69303 \\
\hline & 7.5 & -5.16973 & -6.04706 & -7.13483 \\
\hline
\end{tabular}

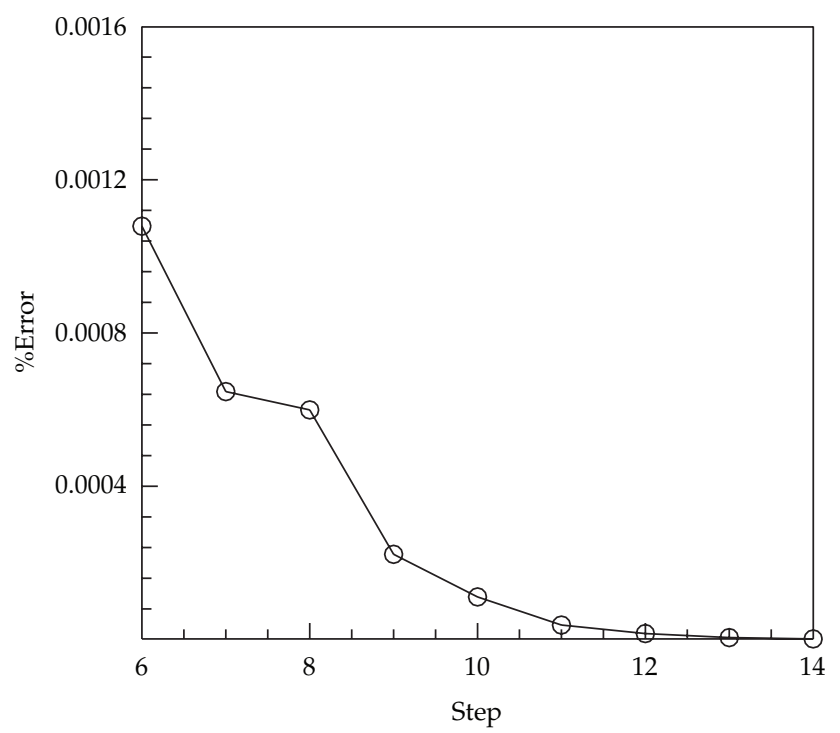

Figure 2: \%Error of $\operatorname{ADM}$ for $f(\eta)$ at different steps when $\alpha=5, \operatorname{Re}=50$, and $\mathrm{Ha}=100$.

Figures 3, 4, and 5 show the magnetic field effect on the velocity profiles for divergent channels. There are good agreements between the numerical solution obtained by the fourthorder Runge-Kutta method and the differential transformation method.

Under magnetic field the Lorentz force effect is in opposite of the momentum's direction that stabilizes the velocity profile.

The results show moderate increases in the velocity with increasing Hartmann numbers at small angle $\left(\alpha=2.5^{\circ}\right)$ and differences between velocity profiles are more noticeable at greater angles. Backflow is excluded in converging channels [42] but it may occur for large Reynolds numbers in diverging channels. For specified opening angle, after a critical Reynolds number, we observe that separation and backflow are started.

Figures 6-8 show the magnetic field effects at constant $\alpha$ and different Reynolds numbers. At $\alpha=5^{\circ}, \operatorname{Re}=75$ with increasing Hartmann number the velocity profile becomes flat and thickness of boundary layer decreases, but at this Reynolds number no backflow is observed as shown in Figure 6. It can be seen in Figure 9 that without magnetic field at $\alpha=5^{\circ}$, $\operatorname{Re}=150$ the backflow starts and that with increasing Hartmann number this phenomenon eliminates. 


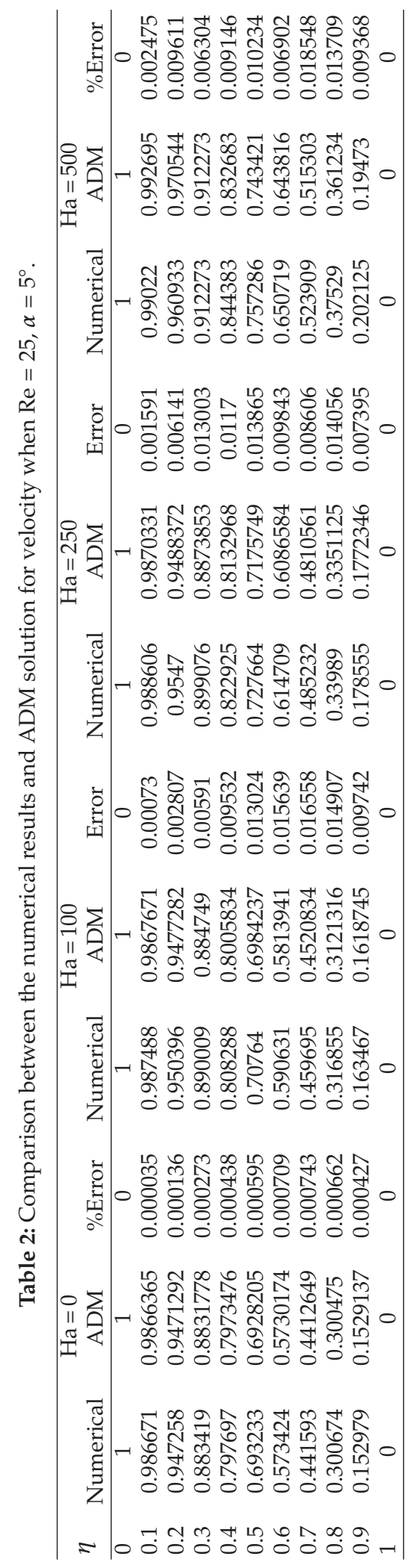




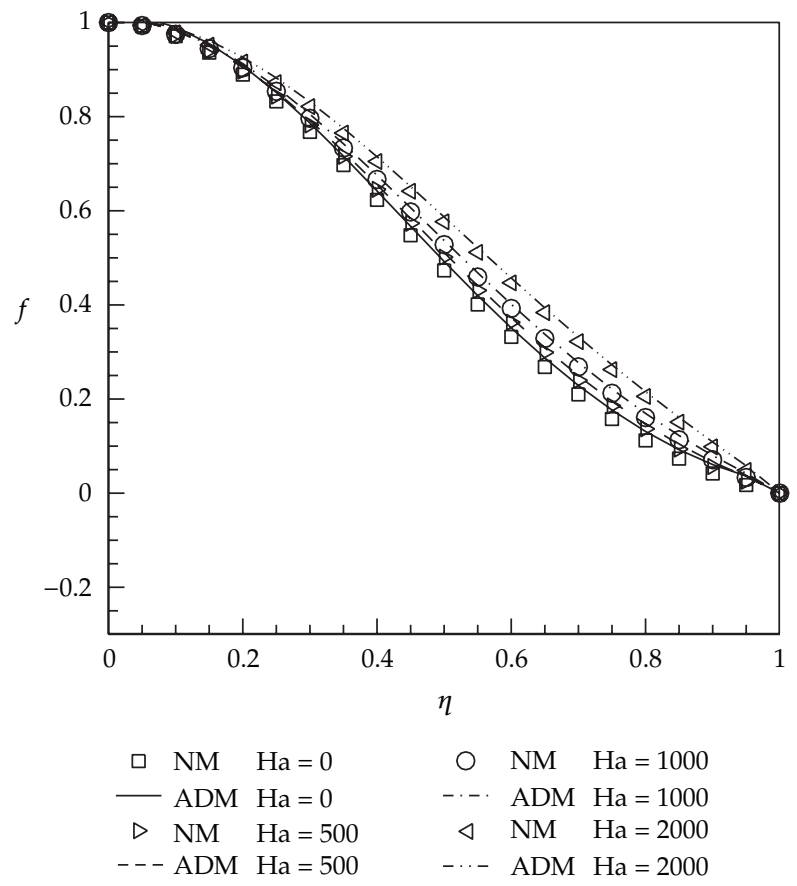

Figure 3: The ADM solution for velocity in divergent channel for $\alpha=2.5^{\circ}, \operatorname{Re}=200$.

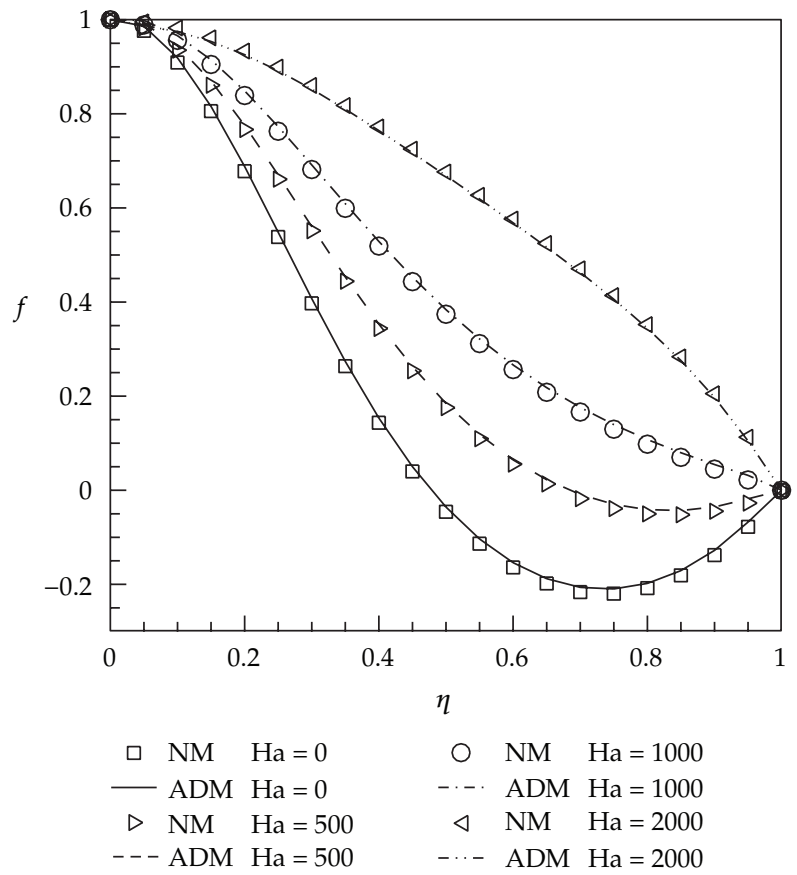

Figure 4: The ADM solution for velocity in divergent channel for $\alpha=5^{\circ}, \operatorname{Re}=200$. 


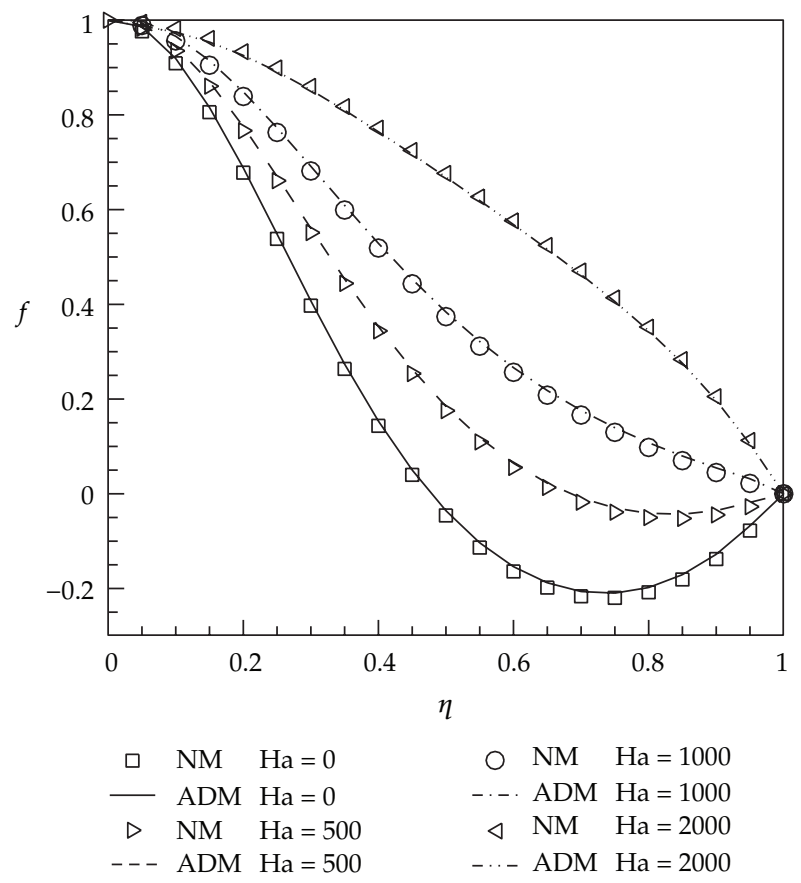

Figure 5: The ADM solution for velocity in divergent channel for $\alpha=7.5^{\circ}, \operatorname{Re}=200$.

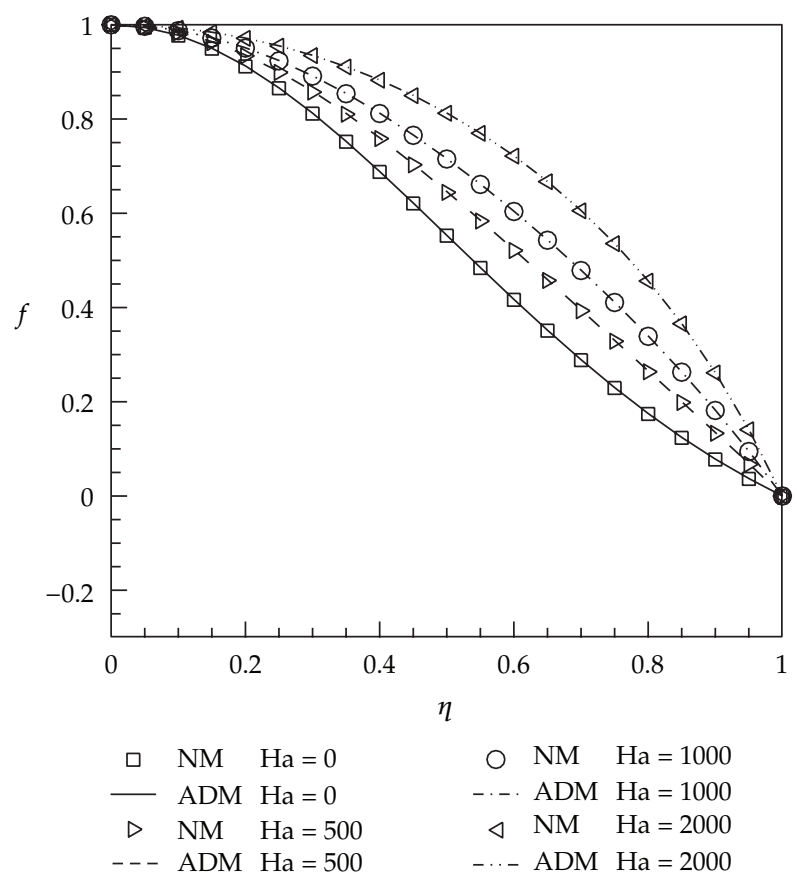

Figure 6: The ADM solution for velocity in divergent channel for $\alpha=5^{\circ}, \operatorname{Re}=75$. 


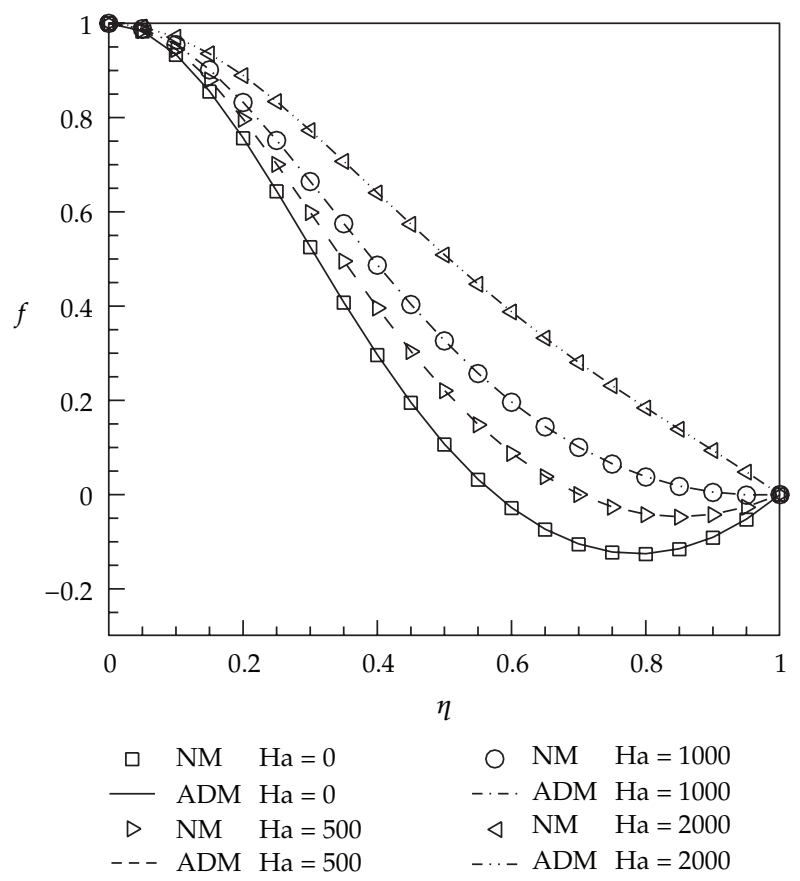

Figure 7: The ADM solution for velocity in divergent channel for $\alpha=5^{\circ}, \operatorname{Re}=225$.

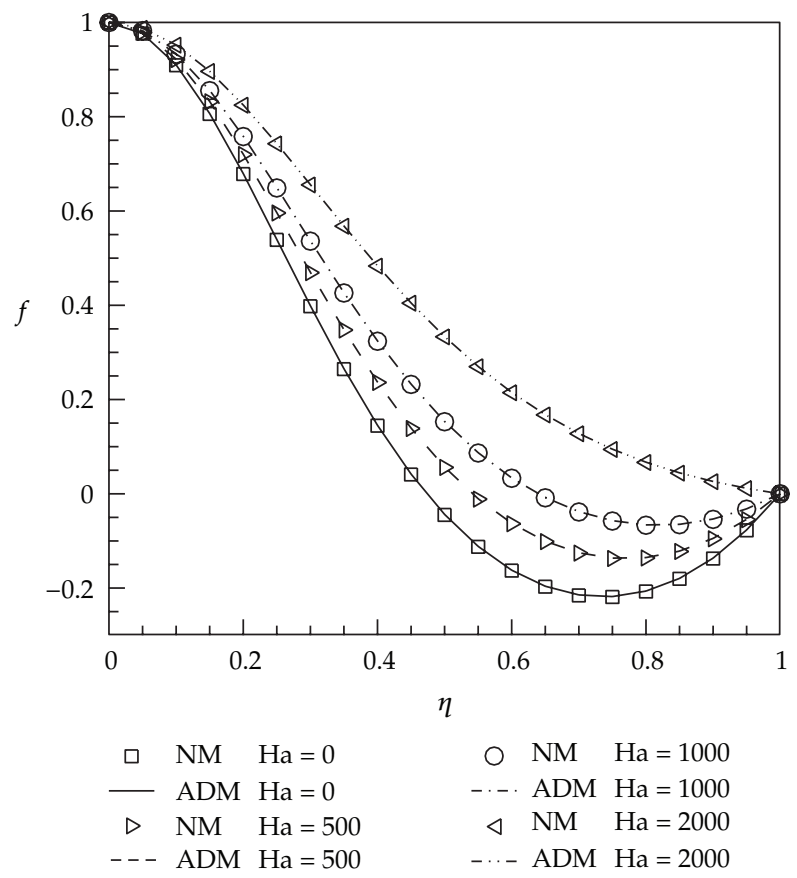

Figure 8: The ADM solution for velocity in divergent channel for $\alpha=5^{\circ}, \operatorname{Re}=300$. 


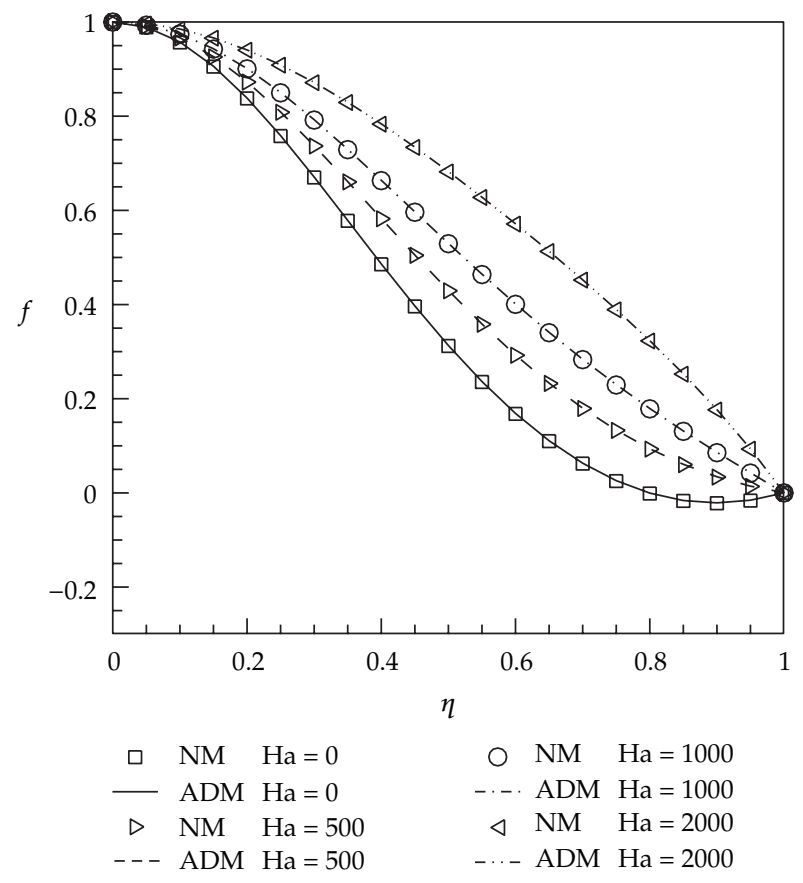

Figure 9: The ADM solution for velocity in divergent channel for $\alpha=5^{\circ}, \operatorname{Re}=150$.

By increasing Reynolds number the backflow expands and so greater magnetic field is needed in order to eliminate it. As shown in Figures 7 and 8 at $\alpha=5^{\circ}, \operatorname{Re}=225$ the back flow eliminates at $\mathrm{Ha}=1000$ while at $\alpha=5^{\circ}, \mathrm{Re}=300$ this occurs at $\mathrm{Ha}=2000$.

\section{Conclusion}

In this paper, magnetohydrodynamic Jeffery-Hamel flow has been solved via a sort of analytical method, Adomian decomposition method (ADM). Also this problem is solved by a numerical method (the Runge-Kutta method of order 4), and some conclusions are summarized as follows.

(a) Adomian decomposition method is a powerful approach for solving MHD JefferyHamel flow in high magnetic field, and it can be observed that there is a good agreement between the present and numerical results.

(b) Increasing Reynolds numbers leads to adverse pressure gradient which causes velocity reduction near the walls.

(c) Increasing Hartmann number will lead to backflow reduction. In greater angles or Reynolds numbers high Hartmann number is needed for the reduction of backflow. 


\title{
Nomenclature
}

\author{
$B_{0}: \quad$ Magnetic field $\left(w b \cdot m^{2}\right)$ \\ $\beta$ : $\quad$ Constant \\ Lu: $\quad$ Linear term \\ $\mathrm{Nu}$ : Nonlinear term \\ $R u$ : The remainder of linear operator \\ $F$ : $\quad$ General nonlinear operator \\ A: Adomian polynominal \\ $f(\eta)$ : Dimensionless velocity \\ Ha: Hartmann number \\ $\rho$ : Density \\ $P: \quad$ Pressure term \\ Re: Reynolds number \\ $r, \theta$ : Cylindrical coordinates \\ $U_{\max }$ : Maximum value of velocity \\ $u, v$ : Velocity components along $x-, y$-axes, respectively.
}

\section{Greek Symbols}
$v$ : Kinematic viscosity
$\tau$ : Viscous stresses
$\alpha$ : Angle of the channel
$\theta$ : Any angle
$\eta$ : Dimensionless angle.

\section{References}

[1] G. B. Jeffery, "The two-dimensional steady motion of a viscous fluid," Philosophical Magazine, vol. 6, pp. 455-465, 1915.

[2] G. Hamel, "Spiralförmige Bewgungen Zäher Flüssigkeiten,” Jahresbericht der Deutschen MathematikerVereinigung, vol. 25, pp. 34-60, 1916.

[3] L. Bansal, Magnetofluiddynamics of Viscous Fluids, Jaipur Publishing House, Jaipur, India, 1994.

[4] J. E. Cha, Y. C. Ahn, and M. H. Kim, "Flow measurement with an electromagnetic flowmeter in twophase bubbly and slug flow regimes," Flow Measurement and Instrumentation, vol. 12, no. 5-6, pp. 329 339, 2002.

[5] M. Tendler, "Confinement and related transport in extrap geometry," Nuclear Instruments and Methods In Physics Research, vol. 207, no. 1-2, pp. 233-240, 1983.

[6] J. Mossino, "Some nonlinear problems involving a free boundary in plasma physics," Journal of Differential Equations, vol. 34, no. 1, pp. 114-138, 1979.

[7] R. Nijsing and W. Eifler, "A computational analysis of transient heat transfer in fuel rod bundles with single phase liquid metal cooling," Nuclear Engineering and Design, vol. 62, no. 1-3, pp. 39-68, 1980.

[8] O. D. Makinde and S. S. Motsa, "Hydromagnetic stability of plane poiseuille flow using chebyshev spectral collocation method," Journal of Institute of Mathematics and Computer Sciences, vol. 12, no. 2, pp. 175-183, 2001.

[9] O. D. Makinde, "Magneto-hydrodynamic stability of plane-Poiseuille flow using multi-deck asymptotic technique," Mathematical and Computer Modelling, vol. 37, no. 3-4, pp. 251-259, 2003.

[10] N. Harada, J. Ikewada, and Y. Terasaki, "Basic studies on an MHD accelerator," The American Institute of Aeronautics and Astronautics, vol. 2175, 2002.

[11] M. Anwari, N. Harada, and S. Takahashi, "Performance study of a magnetohydrodynamic accelerator using air-plasma as working gas," Energy Conversion and Management, vol. 46, no. 15-16, pp. 26052613, 2005. 
[12] J. Jang and S. S. Lee, "Theoretical and experimental study of MHD (magnetohydrodynamic) micropump," Sensors and Actuators, vol. 80, no. 1, pp. 84-89, 2000.

[13] A. Homsy, S. Koster, J. C. T. Eijkel et al., "A high current density DC magnetohydrodynamic (MHD) micropump," The Royal Society of Chemistry, Lab Chip, vol. 5, no. 4, pp. 466-471, 2005.

[14] G. Adomian, "A review of the decomposition method in applied mathematics," Journal of Mathematical Analysis and Applications, vol. 135, no. 2, pp. 501-544, 1988.

[15] H. Jafari and V. Daftardar-Gejji, "Revised Adomian decomposition method for solving systems of ordinary and fractional differential equations," Applied Mathematics and Computation, vol. 181, no. 1, pp. 598-608, 2006.

[16] S. Ghosh, A. Roy, and D. Roy, "An adaptation of Adomian decomposition for numeric-analytic integration of strongly nonlinear and chaotic oscillators," Computer Methods in Applied Mechanics and Engineering, vol. 196, no. 4-6, pp. 1133-1153, 2007.

[17] G. Adomian, "A review of the decomposition method in applied mathematics," Journal of Mathematical Analysis and Applications, vol. 135, no. 2, pp. 501-544, 1988.

[18] H. Jafari and V. Daftardar-Gejji, "Revised Adomian decomposition method for solving a system of nonlinear equations," Applied Mathematics and Computation, vol. 175, no. 1, pp. 1-7, 2006.

[19] H. Bulut, M. Ergut, V. Asil, and R. H. Bokor, "Numerical solution of a viscous incompressible flow problem through an orifice by Adomian decomposition method," Applied Mathematics and Computation, vol. 153, no. 3, pp. 733-741, 2004.

[20] F. M. Allan and M. I. Syam, "On the analytic solutions of the nonhomogeneous Blasius problem," Journal of Computational and Applied Mathematics, vol. 182, no. 2, pp. 362-371, 2005.

[21] L. Wang, "A new algorithm for solving classical Blasius equation," Applied Mathematics and Computation, vol. 157, no. 1, pp. 1-9, 2004.

[22] C. W. Soh, "Non-perturbative semi-analytical source-type solutions of thin-film equation," Applied Mathematics and Computation, vol. 174, no. 2, pp. 1576-1585, 2006.

[23] I. Hashim, "Adomian decomposition method for solving BVPs for fourth-order integro-differential equations," Journal of Computational and Applied Mathematics, vol. 193, no. 2, pp. 658-664, 2006.

[24] I. Hashim, "Comments on "a new algorithm for solving classical Blasius equation," The Journal of Computational and Applied Mathematics, vol. 182, pp. 362-371, 2005.

[25] S. A. Kechil and I. Hashim, "Non-perturbative solution of free-convective boundary-layer equation by Adomian decomposition method," Physics Letters A, vol. 363, no. 1-2, pp. 110-114, 2007.

[26] M. H. Chang, "A decomposition solution for fins with temperature dependent surface heat flux," International Journal of Heat and Mass Transfer, vol. 48, no. 9, pp. 1819-1824, 2005.

[27] C. Arslanturk, "A decomposition method for fin efficiency of convective straight fins with temperature-dependent thermal conductivity," International Communications in Heat and Mass Transfer, vol. 32, no. 6, pp. 831-841, 2005.

[28] F. M. Allan and M. I. Syam, "On the analytic solutions of the nonhomogeneous Blasius problem," Journal of Computational and Applied Mathematics, vol. 182, no. 2, pp. 362-371, 2005.

[29] D. Kaya and A. Yokus, "A decomposition method for finding solitary and periodic solutions for a coupled higher-dimensional Burgers equations," Applied Mathematics and Computation, vol. 164, no. 3, pp. 857-864, 2005.

[30] S. Pamuk, "Solution of the porous media equation by Adomian's decomposition method," Physics Letters A, vol. 344, no. 2-4, pp. 184-188, 2005.

[31] F. M Allan and K. Al-Khaled, "An approximation of the analytic solution of the shock wave equation," Journal of Computational and Applied Mathematics, vol. 192, no. 2, pp. 301-309, 2006.

[32] V. Daftardar-Gejji and H. Jafari, "An iterative method for solving nonlinear functional equations," Journal of Mathematical Analysis and Applications, vol. 316, no. 2, pp. 753-763, 2006.

[33] D. Lesnic, "Decomposition methods for non-linear, non-characteristic Cauchy heat problems," Communications in Nonlinear Science and Numerical Simulation, vol. 10, no. 6, pp. 581-596, 2005.

[34] Y. Zhu, Q. Chang, and S. Wu, "A new algorithm for calculating Adomian polynomials," Applied Mathematics and Computation, vol. 169, no. 1, pp. 402-416, 2005.

[35] X. G. Luo, "A two-step Adomian decomposition method," Applied Mathematics and Computation, vol. 170 , no. 1 , pp. 570-583, 2005.

[36] X. Zhang, "A modification of the Adomian decomposition method for a class of nonlinear singular boundary value problems," Journal of Computational and Applied Mathematics, vol. 180, no. 2, pp. 377$389,2005$. 
[37] D. Kaya and A. Yokus, "A comparison of partial solutions in the decomposition method for linear and nonlinear partial differential equations," Mathematics and Computers in Simulation, vol. 60, no. 6, pp. 507-512, 2002.

[38] W. I. Axford, "The mahnetohydrodynamic Jeffery-Hamel problem for a weakly conducting fluid," The Quarterly Journal of Mechanics and Applied Mathematics, vol. 14, pp. 335-351, 1961.

[39] M. Esmaeilpour and D. D. Ganji, "Solution of the Jeffery-Hamel flow problem by optimal homotopy asymptotic method," Computers and Mathematics with Applications, vol. 59, no. 11, pp. 3405-3411, 2010.

[40] Z. Z. Ganji, D. D. Ganji, and M. Esmaeilpour, "Study on nonlinear Jeffery-Hamel flow by He's semi-analytical methods and comparison with numerical results," Computers and Mathematics with Applications, vol. 58, no. 11-12, pp. 2107-2116, 2009.

[41] O. D. Makinde and P. Y. Mhone, "Temporal stability of small disturbances in MHD Jeffery-Hamel flows," Computers and Mathematics with Applications, vol. 53, no. 1, pp. 128-136, 2007.

[42] Z. Z. Ganji, D. D. Ganji, and M. Esmaeilpour, "Study on nonlinear Jeffery-Hamel flow by He's semi-analytical methods and comparison with numerical results," Computers and Mathematics with Applications, vol. 58, no. 11-12, pp. 2107-2116, 2009. 


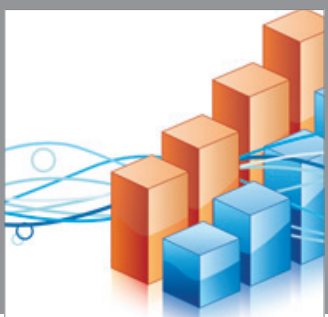

Advances in

Operations Research

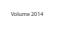

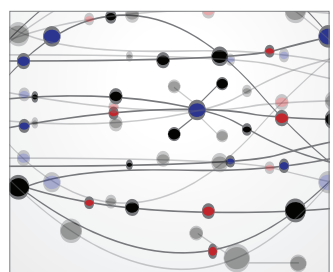

\section{The Scientific} World Journal
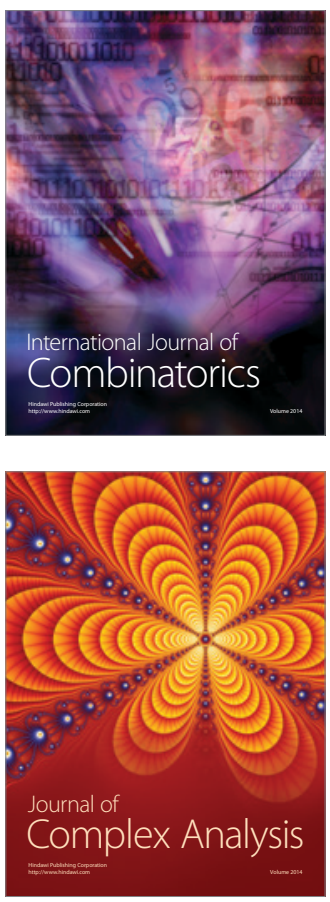

International Journal of

Mathematics and

Mathematical

Sciences
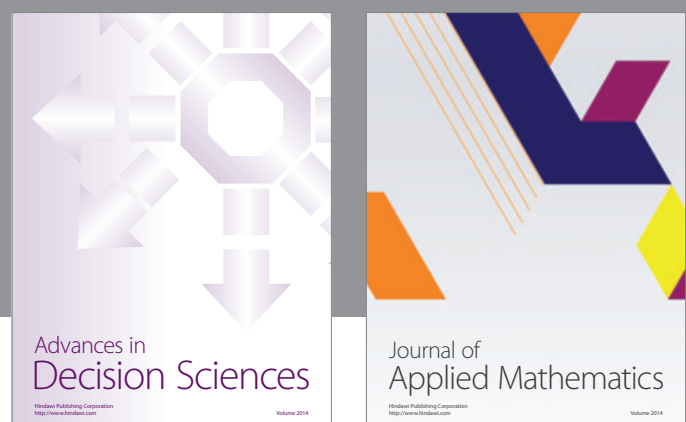

Journal of

Applied Mathematics
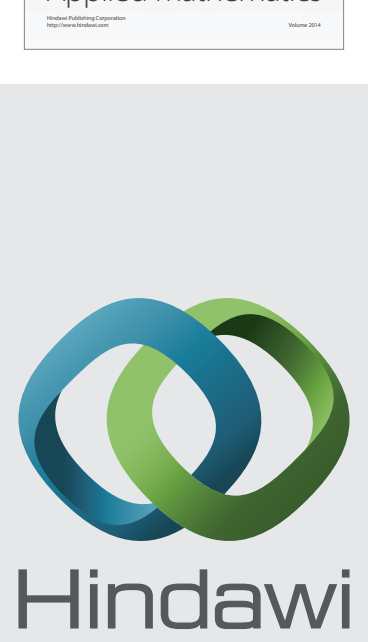

Submit your manuscripts at http://www.hindawi.com
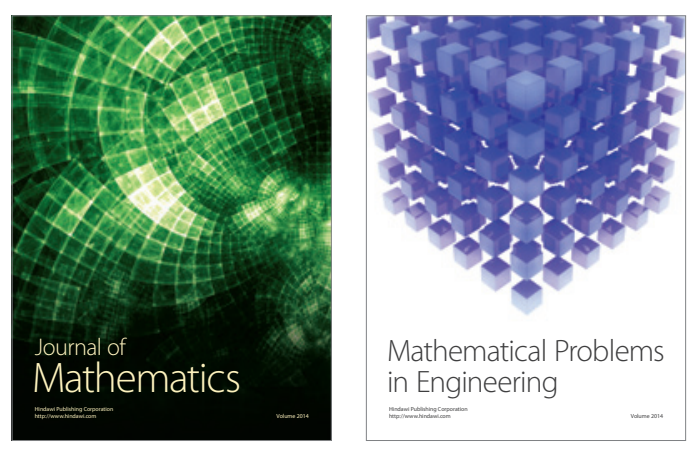

Mathematical Problems in Engineering
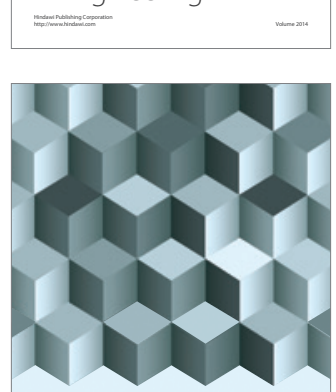

Journal of

Function Spaces
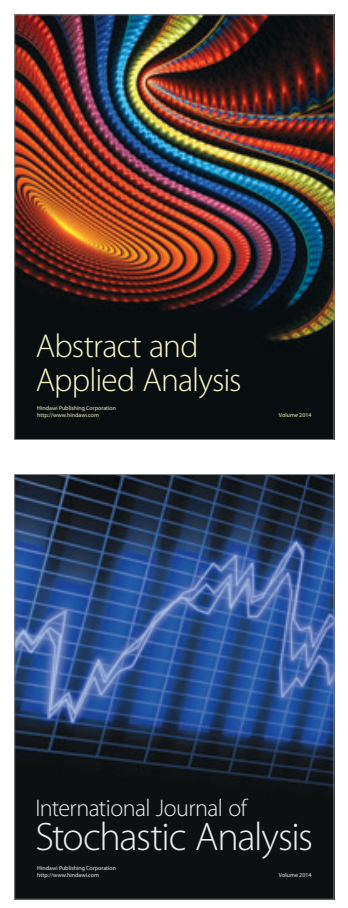

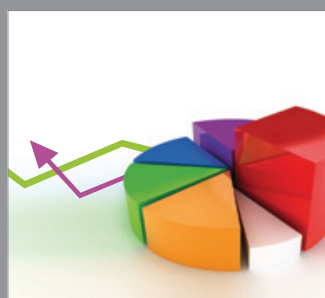

ournal of

Probability and Statistics

Promensencen
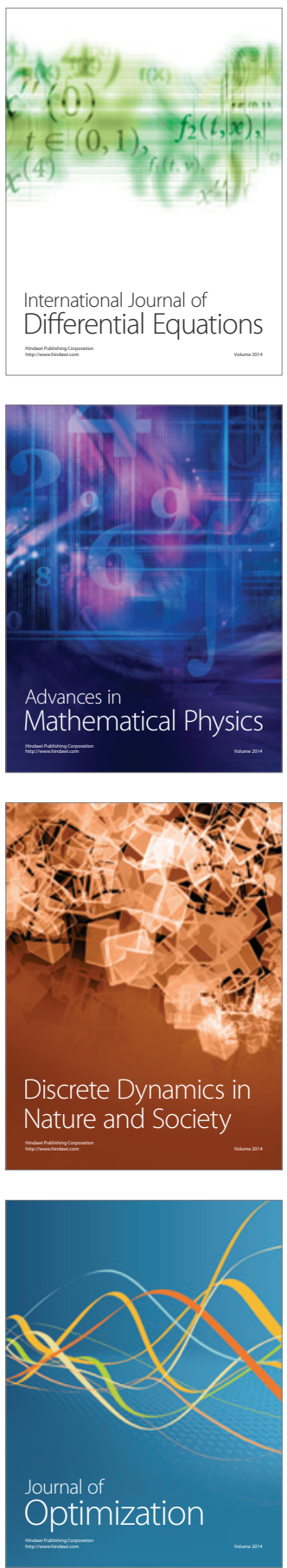